\title{
Untersuchungen über tierische Leimstoffe.
}

\author{
III. Mitteilung.
}

Das Verhalten gegen Salzlösungen.

Von

W1. S. Sadikoff aus St. Petersburg.

(Aus der chemischen Abteilung des physiologischen Instituts in Berlin.)

(Der Redaktion zugegangen am 29. Dezember 1903.)

Im folgenden sollen einige Beobachtungen kurz mitgeteilt werden, die von mir über das Verhalten verschiedener Leimstoffe gegen Salzlösungen angestellt worden sind. Die Veröffentlichung trägt mehr den Charakter einer vorläufigen Mitteilung und hat den Nebenzweck, mir das ungestörte Arbeiten auf diesem Gebiete zu sichern.

1. Verhalten verschiedener Leimstoffe in bezug auf ihre Löslichkeit in Salzlösungen. Im Anschluß an die Arbeiten anderer Autoren Pascheles, ${ }^{1}$ ) Pauli, ${ }^{2}$ ) Levites ${ }^{8}$ ) über die Einwirkung von Salzen auf Gelatinelösungen habe ich das Lösungsvermögen verschiedener starker Salzlösungen auf die von $\mathrm{mir}^{4}$ ) dargestellten und analysierten Leimstoffe untersucht. Die geprüften Substanzen waren käufliche gereinigte Gelatine, Sehnentrypsinglutin A, Nasen-, Tracheal- und Ohrenknorpelglutein und kamen in Form feiner Pulver, wie man sie durch Zerreiben der durch Alkohol aus wässeriger Lösung erhaltenen und getrockneten Niederschläge gewinnt, zur Anwendung. Die Salzlösungen waren 50\% ige wässerige oder, wenn die Löslichkeit eine geringere war, kalt gesättigte wässerige. Die

1) Arch. f. d. ges. Physiol., Bd. 71, S. 333.

$\left.{ }^{2}\right)$ Beitr. zur chem. Physiol. u. Pathol., Bd. 2, S. 1.

3) Journ. d. russ. phys. chem. Ges., Bd. 34, S. 110 u. 439.

4) Diese Zeitschr., Bd. XXXIX, S. 396 u. 411. 
Temperatur betrug $18^{\circ}$. Die Ergebnisse der Versuche sind in folgender Tabelle zusammengestellt. + bedeutet löslich; - bedeutet unlöslich oder teilweise löslich; kein Zeichen bedeutet, daß mit dem Salz kein Versuch ausgeführt worden ist.

\begin{tabular}{|c|c|c|c|c|c|c|c|c|c|c|c|c|c|}
\hline & $\vec{\forall}$ & $\overrightarrow{\tilde{J}}$ & $\overbrace{}^{\infty}$ & 总 & 俚 & ตี & $\begin{array}{l}0^{\infty} \\
\mathbf{z}^{\infty} \\
\mathbf{m}^{\circ}\end{array}$ & $\sum_{\substack{2 \\
2}}^{2}$ & $\sum_{i=1}^{\infty}$ & $0^{\infty}$ & $\begin{array}{l}\vec{j} \\
\text { 营 }\end{array}$ & $\stackrel{0}{0}_{\substack{\infty \\
:}}^{\infty}$ & స్త్ర \\
\hline $\begin{array}{c}\text { Gereinigte } \\
\text { Handelsgelatine }\end{array}$ & 一 & + & 一 & - & + & + & + & + & & & & & \\
\hline $\begin{array}{l}\text { Sehnentrypsin- } \\
\text { glutin A }\end{array}$ & - & - & - & - & + & + & + & + & + & + & + & + & $1+$ \\
\hline Nasenglutein & + & + & + & + & + & + & + & + & + & + & + & & \\
\hline Trachealglutein & + & + & + & + & + & + & + & + & + & + & + & & \\
\hline Ohrenglutein & \begin{tabular}{|c|} 
schwer \\
+
\end{tabular} & $t$ & $\begin{array}{c}\text { schrer } \\
+\end{array}$ & $\begin{array}{c}\text { schwer } \\
+\end{array}$ & + & + & + & + & + & + & + & & \\
\hline
\end{tabular}

Ein Unterschied zeigt sich also nur in dem Verhalten gegen $\mathrm{KCl}, \mathrm{NaCl}, \mathrm{KNO}_{2}$ und $\mathrm{KCN}$, aber hier tritt er sehr deutlich hervor, insofern die Gluteine von den Lösungen dieser 4 Salze aufgelöst werden, während das Sehnenglutin in ihnen ganz oder teilweise unlöslich ist und die Handelsgelatine nur von der Kochsalzlösung völlig gelöst wird.

2. Verhalten der gereinigten Gelatine gegen Kaliumnitrit- und Kaliumchloridlösungen. Schüttelt man trockene Gelatine mit neutraler 50\%iger Kaliumnitritlösung, so geht ein Teil in Lösung, ein anderer Teil bleibt ungelöst und kann auch durch neue Kaliumnitritlösung und bei anhaltendem Schütteln nicht in Lösung gebracht werden. Der ungelöste Teil sowie die zunächst zugefügte Salzlösung nehmen eine Rosafarbe an; die späteren Portionen der Salzlösung, welche keine Gelatine mehr aufnehmen, färben sich auch nicht mehr rosa. Die Färbung rührt vielleicht von schwer entfernbaren Fäulnisprodukten her, welche der Handelsgelatine beigemengt sind. Bei Benutzung einer kaltgesättigten Kaliumchloridlösung 
macht man ganz dieselbe Beobachtung, nur daß hier keine Farbenerscheinungen auftreten.

Man kann also mit Hilfe dieser Salze die Gelatine zerlegen.

3. Einwirkung der Erhitzung auf die Salzlöslichkeit. Erhitzt man die trockenen Präparate, so verlieren sie allmählich ihre Löslichkeit in Salzlösungen, während (bei den von mir benutzten Versuchsbedingungen) die Löslichkeit in heißem Wasser erhalten bleibt. Die Einzelheiten ergeben sich aus folgender Tabelle, aus der man gleichzeitig ersehen wird, daß auch in dieser Beziehung die verschiedenen Leimstoffe Unterschiede zeigen.

Gereinigte Handelsgelatine.

\begin{tabular}{|c|c|c|c|c|c|c|c|c|c|c|c|c|}
\hline & & $\vec{v}$ & 雨 & 党| & 急 & صี & $\begin{array}{l}0^{\infty} \\
z^{-*} \\
\text { 点 }\end{array}$ & $\underbrace{\infty}_{\forall}$ & $\sum_{i=1}^{\infty}$ & $\bigcap^{\infty}$ & $\begin{array}{l}\vec{J} \\
\vec{Z}^{*}\end{array}$ & 我 \\
\hline $\begin{array}{l}\text { Nach dem Tr } \\
\text { im Vacuum }\end{array}$ & $\begin{array}{l}\text { ocknen } \\
\text { bei } 18^{\circ}\end{array}$ & - & + & & + & + & + & + & & & & \\
\hline \multirow{2}{*}{$\begin{array}{c}\text { Nach } 3 \text { stünd. } \\
\text { Erhitzen } \\
\text { auf } 135^{\circ}\end{array}$} & \multirow[t]{2}{*}{ bei $18^{\circ}$} & & & & $\begin{array}{c}\text { sehwer } \\
+\end{array}$ & - & - & - & & & & \\
\hline & & & & & + & + & + & + & & & & \\
\hline \multicolumn{2}{|c|}{$\begin{array}{c}\text { Nach } 6 \text { stünd. Erhitzen } \\
\text { auf } 135^{\circ} \text { bei } 37^{\circ}\end{array}$} & & - & & - & - & - & - & - & - & - & \\
\hline \multirow{2}{*}{$\begin{array}{c}\text { Nach 12stünd. } \\
\text { Erhitzen } \\
\text { auf } 110^{\circ}\end{array}$} & \multirow{2}{*}{$\begin{array}{l}\text { bei } 18^{\circ} \\
\text { bei } 37^{\circ}\end{array}$} & & & & $\begin{array}{c}\text { sehror } \\
+\end{array}$ & & + & $\begin{array}{c}\text { schrer } \\
+\end{array}$ & - & $\left|\begin{array}{c}\text { sebror } \\
+\end{array}\right|$ & - & \\
\hline & & & - & & + & & & + & $\begin{array}{c}\text { sehror } \\
+\end{array}$ & + & + & \\
\hline \multirow{2}{*}{$\begin{array}{c}\text { Nach } 24 \text { stünd. } \\
\text { Erhitzen } \\
\text { auf } 110^{\circ}\end{array}$} & & & - & & - & - & - & - & - & - & - & - \\
\hline & bei $37^{\circ}$ & & & & + & $\begin{array}{l}\text { sckwer } \\
+\end{array}$ & $\begin{array}{c}\text { schwor } \\
+\end{array}$ & + & & $\left|\begin{array}{c}\text { sehwer } \\
+\end{array}\right|$ & $\left|\begin{array}{c}\text { schver } \\
+\end{array}\right|$ & \\
\hline $\begin{array}{l}\text { Nach } 30 \text { stünd.F } \\
\text { auf } 110^{\circ} \text { be }\end{array}$ & $\begin{array}{l}\text { Erhitzen } \\
\text { i } 37^{\circ}\end{array}$ & & & & - & - & - & - & - & - & - & \\
\hline
\end{tabular}


Sehnentrypsinglutin A.

\begin{tabular}{|c|c|c|c|c|c|c|c|c|c|c|c|c|c|}
\hline . & $\vec{U}$ & $\begin{array}{l}\vec{\pi} \\
\tilde{z}\end{array}$ & $0^{\circ}$ & 总 & $\vec{\infty}$ & $\stackrel{9}{*}$ & $\mid \begin{array}{c}0^{\infty} \\
z^{+} \\
\text {穵 }\end{array}$ & 总 & $\sum_{i=1}^{\infty}$ & $0^{\infty}$ & 荘 & $0^{\infty}$ & 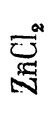 \\
\hline $\begin{array}{l}\text { Nach dem Trocknen } \\
\text { im Vacuum bei } 18^{\circ}\end{array}$ & - & - & - & - & +1 & + & + & + & + & + & + & + & + \\
\hline $\begin{array}{l}\text { Nach } 3 \text { stünd. Erhitzen } \\
\text { auf } 135^{\circ} \text { bei } 37^{\circ}\end{array}$ & - & - & - & - & - & - & - & - & - & - & - & $1-$ & - \\
\hline
\end{tabular}

Nasenknorpelglutein.

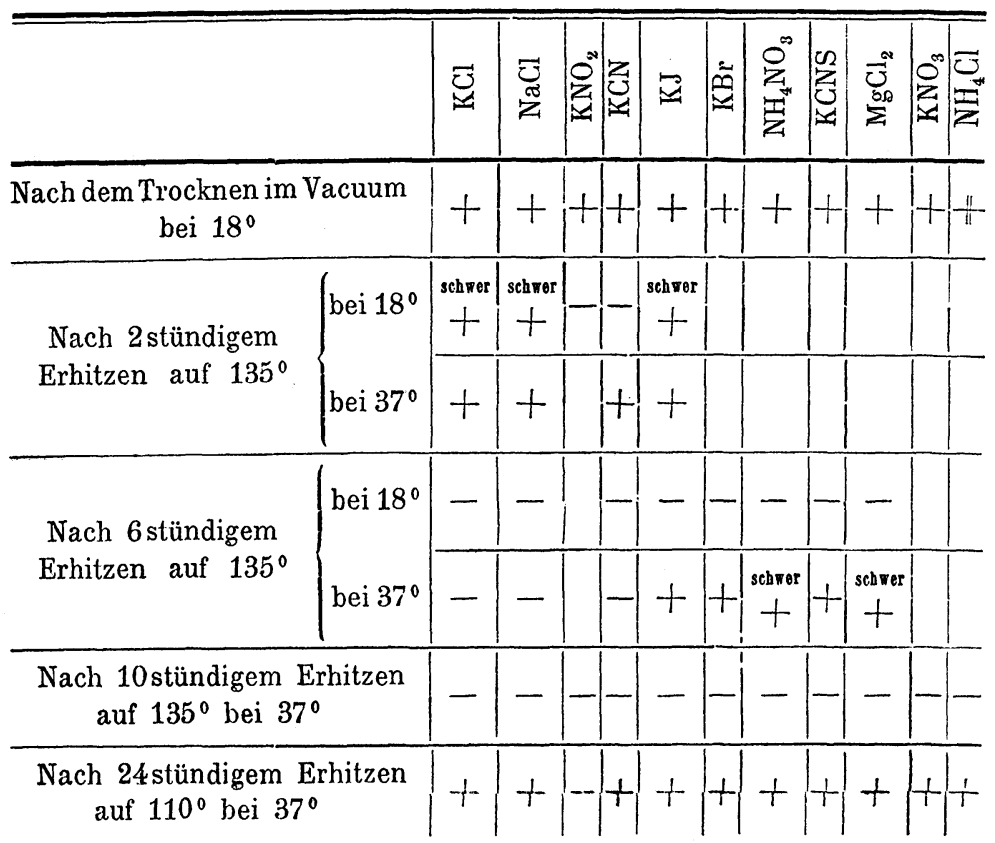

Man beobachtet hier an der Hand des Verhaltens zu Salzlösungen eine während des Erhitzens sich allmählich vollziehende Veränderung des Glutins, welche vermutlich in einer zunehmenden Kondensation unter Wasseraustritt besteht. Ein noch höherer Grad von gleichsinniger Veränderung wurde von Hofmeister ${ }^{1}$ ) durch anhaltendes Erhitzen auf $130^{\circ}$ erreicht.

1) Diese Zeitschrift, Bd. II, S. 313. 
Er äußerte sich darin, daß das Präparat (gereinigte käufliche Gelatine) nunmehr erst bei 15-20 stündigem Kochen mit Wasser oder bei 2 stündigem Erhitzen mit Wasser in geschlossenem Rohr auf $120^{\circ}$ in Lösung ging. Die von mir beobachteten Zustände dürften als Zustände geringerer Kondensation aufzufassen sein, bei denen noch Löslichkeit in heißem Wasser vorhanden ist, aber die Löslichkeit in Salzlösungen schon abgenommen hat. 